\title{
Introduction to Different PET Radiopharmaceuticals and Hybrid Modalities (PET/CT and PET/MRI)
}

\author{
Luca Giovanella, Lisa Milan, and Arnoldo Piccardo
}

\subsection{Physical Principles of Positron Emission Tomography and Hybrid Modalities}

Positron Emission Tomography (PET) is an imaging technique performed by using positron emitting radiotracers. Positron decay occurs with neutron-poor radionuclides and consists in the conversion of a proton into a neutron with the simultaneous emission of a positron $(\beta+)$ and a

L. Giovanella $(\bowtie)$

Clinic of Nuclear Medicine and Molecular Imaging, Imaging Institute of Southern Switzerland,

Ente Ospedaliero Cantonale, Bellinzona, Switzerland

Laboratory of Radiomics and Predictive Imaging, Imaging Institute of Southern Switzerland,

Ente Ospedaliero Cantonale, Bellinzona, Switzerland

Clinic of Nuclear Medicine, University Hospital and University of Zurich, Zurich, Switzerland e-mail: luca.giovanella@eoc.ch

L. Milan

Clinic of Nuclear Medicine and Molecular Imaging, Imaging Institute of Southern Switzerland,

Ente Ospedaliero Cantonale, Bellinzona, Switzerland

Laboratory of Radiomics and Predictive Imaging, Imaging Institute of Southern Switzerland,

Ente Ospedaliero Cantonale, Bellinzona, Switzerland
A. Piccardo
Division of Nuclear Medicine, Ente Ospedaliero
"Ospedali Galliera", Genoa, Italy

neutrino $(\nu)$. The positron has a very short lifetime, and after the annihilation with an electron simultaneously produces two high-energy photons $(E=511 \mathrm{keV})$ in approximately opposite directions that are detected by an imaging camera. The PET scanning is based on the so-called annihilation coincidence detection (ACD) of the $511 \mathrm{keV} \gamma$-rays after the annihilation. Tomographic images are formed collecting data from many angles around the patient by scintillating crystals optically coupled to a photon detectors used to localize the position of the interaction and the amount of absorbed energy in the crystals (Table 1.1) [1].

Table 1.1 Properties of PET scintillator crystals

\begin{tabular}{|c|c|c|c|c|c|}
\hline & $\mathrm{NaI}(\mathrm{Tl})$ & BGO & LSO & GSO & LYSO \\
\hline $\begin{array}{l}\text { Effective atomic } \\
\text { number }(Z)\end{array}$ & 50 & 73 & 66 & 59 & 60 \\
\hline$\mu\left(\mathrm{cm}^{-1}\right)$ & 0.34 & 0.95 & 0.87 & 0.70 & 0.86 \\
\hline $\begin{array}{l}\text { Index of } \\
\text { refraction }\end{array}$ & 1.85 & 2.15 & 1.82 & 1.85 & 1.81 \\
\hline Density $\left(\mathrm{g} / \mathrm{cm}^{3}\right)$ & 3.67 & 7.13 & 7.40 & 6.71 & 7.30 \\
\hline $\begin{array}{l}\text { Photon yield } \\
\text { (per } \mathrm{kVp} \text { ) }\end{array}$ & 38 & 8 & $20-30$ & $\begin{array}{l}12- \\
15\end{array}$ & 25 \\
\hline $\begin{array}{l}\text { Peak } \\
\text { wavelength } \\
(\mathrm{nm})\end{array}$ & 410 & 480 & 420 & 430 & 420 \\
\hline $\begin{array}{l}\text { Decay time } \\
\text { constant (ns) }\end{array}$ & 230 & 300 & 40 & 65 & 41 \\
\hline $\begin{array}{l}\text { Energy } \\
\text { resolution (\% at } \\
511 \mathrm{keV})\end{array}$ & $7.8 \%$ & $20 \%$ & $10.1 \%$ & $9.5 \%$ & $20 \%$ \\
\hline Hygroscopic & Yes & No & No & No & No \\
\hline
\end{tabular}


Table 1.2 The PET scanner performance and the intrinsic PET limitations

\begin{tabular}{|c|c|c|}
\hline & Definition & Intrinsic limitation \\
\hline $\begin{array}{l}\text { Spatial } \\
\text { resolution }\end{array}$ & $\begin{array}{l}\text { The minimum distance } \\
\text { between two points in an } \\
\text { image that can be } \\
\text { detected by a scanner }\end{array}$ & $\begin{array}{l}\text { Positron range: Error occurs in the localization of the true position of the } \\
\text { positron emission resulting in the degradation of the spatial resolution } \\
\text { Non-collinearity: The two } 511 \mathrm{keV} \text { photons are not emitted at exactly } \\
\text { opposite directions: This deviation can reach a value of } \pm 0.25^{\circ} \text { at maximum } \\
\text { detector size and its intrinsic resolution: resolution is better in the centre of } \\
\text { the FOV than at the edge }\end{array}$ \\
\hline Sensitivity & $\begin{array}{l}\text { Number of counts per } \\
\text { unit time detected by the } \\
\text { system for a unitary } \\
\text { activity }\end{array}$ & $\begin{array}{l}\text { Geometric efficiency: the fraction of emitted radiation that hits the detector } \\
\text { and it depends on the source to detector distance, on the diameter of the ring } \\
\text { and on the number of detectors in each ring } \\
\text { Intrinsic efficiency: the fraction of radiation that reaches the detector and is } \\
\text { acquired. It depends on the scintillation decay time and the stopping power } \\
\text { of the detector }\end{array}$ \\
\hline $\begin{array}{l}\text { Noise- } \\
\text { equivalent } \\
\text { count rate }\end{array}$ & $\begin{array}{l}\text { Parameter used to define } \\
\text { the noise and to compare } \\
\text { the PET performance }\end{array}$ & $\begin{array}{l}\text { Takes into account the effects introduced by scatter and random } \\
\text { coincidences }\end{array}$ \\
\hline Contrast & $\begin{array}{l}\text { Difference in counts } \\
\text { between an area of } \\
\text { interest and its } \\
\text { surroundings }\end{array}$ & Scatter, random and out-of-FOV radiation \\
\hline
\end{tabular}

The key properties that characterize the PET scanner performances are the spatial resolution, the sensitivity, the Noise-Equivalent Count Rate (NECR) and the contrast [2]. The projection data acquired in the form of sinograms are affected by a number of factors that contribute to the degradation of the final images and hence to the PET scanner performances, as reported in Table 1.2.

Two classes of reconstruction techniques exist: the analytical and the iterative methods [3]. The most used analytical method is the backprojection. To compensate the blurring, a filter is applied to the projections before they are back-projected onto the image [i.e. filtered backprojection (FBP)]. In modern scanners, the image reconstruction algorithms are based on iterative methods, which approach the true image by means of successive estimations, in order to converge to an image that best represents the original object. These algorithms are known as expectation maximization (EM) and Ordered Subset Expectation Maximization (OSEM) algorithm [4].

\subsection{Hybrid Scanners: PET/CT and PET/MRI}

Combined PET/CT systems were commercially available from 2001 and in a very short time the dedicated PET scanner was completely replaced by hybrid PET/CT. The ability of hybrid PET/CT systems to accurately identify the anatomic location of diseases and to provide attenuationcorrected images are the main causes of their rapid success and diffusion [5]. Modern clinical $\mathrm{PET} / \mathrm{CT}$ consists in a high-performance PET scanner in-line with a high-performance CT scanner arranged in sequential gantries. The scanner table moves along the gantry axis in order to subsequently acquire CT and then PET data. A software integrated in the system has to check if the patient bed undergoes some deflections during the translation [6]. Images of tissue attenuation from the CT scan are used to derive the PET attenuation correction factors. The latter depends on the energy of the photons: since CT X-rays and PET $\gamma$-rays have an energy of $70 \mathrm{keV}$ and $511 \mathrm{keV}$, 
Table 1.3 The characteristics of the three commercially available PET/MRI scanners

\begin{tabular}{|c|c|c|c|}
\hline & $\begin{array}{l}\text { Siemens biograph } \\
\text { mMR }\end{array}$ & Philips ingenuity & GE Signa \\
\hline PET/MR technology & Integrated & Sequential & Integrated \\
\hline \multicolumn{4}{|l|}{ PET } \\
\hline Scintillator & LSO & LYSO & LBS \\
\hline Crystal size (mm) & $4 \times 4 \times 20$ & $4 \times 4 \times 22$ & $4 \times 5.3 \times 25$ \\
\hline Crystal number & 28,672 & 28,336 & 20,160 \\
\hline Photodetector & APD & PMT & SiPM \\
\hline TOF & No & Yes & Yes \\
\hline Energy resolution (\%) & 14.5 & 12 & 10.5 \\
\hline Energy window (keV) & $430-610$ & $460-665$ & $425-650$ \\
\hline Time resolution (ns) & 2.93 & 0.53 & 0.39 \\
\hline Coincidence window (ns) & 5.86 & 6.00 & 4.57 \\
\hline Transaxial FOV (cm) & $59.4 \mathrm{~cm}$ & // & $60 \mathrm{~cm}$ \\
\hline Axial FOV & $25.8 \mathrm{~cm}$ & 18 & $25 \mathrm{~cm}$ \\
\hline Sensitivity (kcps/MBq) & 15.0 & 7.0 & 22.2 \\
\hline Scatter fraction $(\%)$ & 37.9 & 26.0 & 43.4 \\
\hline Peak NECR (kcps@ @Bq/mL) & 184@23.1 & 88.5@13.7 & 218@17.7 \\
\hline \multicolumn{4}{|l|}{ MR } \\
\hline Field strength $(\mathrm{T})$ & 3 & 3 & 3 \\
\hline Bore $(\mathrm{cm})$ & 60 & 60 & 60 \\
\hline $\mathrm{FOV}\left(\mathrm{cm}^{3}\right)$ & $50 \times 50 \times 50$ & $50 \times 50 \times 45$ & $50 \times 50 \times 50$ \\
\hline Gradient mT/m & 45 & 40 & 44 \\
\hline Slew rate $(\mathrm{T} / \mathrm{m}) / \mathrm{s}$ & 200 & 100 & 200 \\
\hline
\end{tabular}

respectively, the attenuation correction factor obtained from CT must be scaled to the $511 \mathrm{keV}$ photons applying a scaling factor defined by the ratio of the $\mu$ of the $511 \mathrm{keV}$ photons to that of the $70 \mathrm{keV} \mathrm{X}$-rays in a given tissue [1].

PET/MRI is a multi-modality technology combining the functional information of PET with the soft-tissue contrast of MRI. Actually, two approaches are implemented in the commercial PET/MRI scanners: sequential PET/MRI [7-9]. The characteristics of the three commercial PET/MRI scanners are summarized in Table 1.3.

\subsection{Positron Emission Tomography Radiopharmaceuticals}

Radiopharmaceuticals are radiolabelled molecules consisting in a molecular structure and a radioactive nuclide. The first one defines the pharmacokinetics and dynamics within the organism, while the latter is responsible for a detectable signal and for the consequent image visualization [10]. To maintain the stability of these two components, a linker may be necessary. The most important PET nuclides and their physical characteristics are summarized below:

- Carbon-11 $\left({ }^{11} \mathrm{C}\right)$ has a physical half-life of about $20 \mathrm{~min}$ and decays by $\beta^{+}$emission $(99.75 \%)$ and by electron capture $(0.25 \%)$ to the ground state of the stable nuclide Boron-11 $\left({ }^{11} \mathrm{~B}\right) . \beta^{+}$average energy is $386 \mathrm{keV}$, corresponding to a mean range in water of $1.3 \mathrm{~mm}$. ${ }^{11} \mathrm{C}$ can be produced by different nuclear reactions; however, the main production mode is targeting Nitrogen-14 $\left({ }^{14} \mathrm{~N}\right)$ with cyclotron accelerated protons: ${ }^{14} \mathrm{~N}(\mathrm{p}, \alpha){ }^{14} \mathrm{C}$.

- Fluorine-18 $\left({ }^{18} \mathrm{~F}\right)$ has a physical half-life of about 110 min and decays by $\beta^{+}$emission $(96.86 \%)$ and electron capture (3.14\%) directly to the ground state of the stable 
nuclide Oxygen-18 $\left({ }^{18} \mathrm{O}\right) . \beta^{+}$average energy is $250 \mathrm{keV}$, corresponding to a mean range in water of $0.6 \mathrm{~mm} .{ }^{18} \mathrm{~F}$ can be produced by different nuclear reactions; however, the main production mode is targeting Oxygen-18 with cyclotron accelerated protons: ${ }^{18} \mathrm{O}(\mathrm{p}, \mathrm{n}){ }^{18} \mathrm{~F}$.

- Gallium-68 $\left({ }^{68} \mathrm{Ga}\right)$ has a physical half-life of about $67.8 \mathrm{~min}$ and decays by $\beta^{+}$emission $(88.88 \%)$ and by electron capture $(11.11 \%)$ into ${ }^{68} \mathrm{Zn}$. $\beta^{+}$average energy is $830 \mathrm{keV}$, corresponding to a mean range in water of $3.6 \mathrm{~mm} .{ }^{18} \mathrm{Ga}$ can be produced by different nuclear reactions; however, the main production mode is using a Germanium-68 $\left({ }^{68} \mathrm{Ge}\right)$ ${ }^{68} \mathrm{Ga}$ generator.

- Iodine-124 ( $\left.{ }^{124} \mathrm{I}\right)$ has a physical half-life of about 4.2 days and decays by $\beta^{+}$emission $(23 \%)$ and by electron capture $(77 \%)$ to the excited level and the ground state of Tellurium-124 $\left({ }^{124} \mathrm{Te}\right) . \beta^{+}$average energy is $836 \mathrm{keV}$, corresponding to a mean range in water of $3.4 \mathrm{~mm} .{ }^{124} \mathrm{I}$ can be produced by different nuclear reactions; however, ${ }^{124} \mathrm{Te}(\mathrm{p}, \mathrm{n})$ reaction gives the purest form of ${ }^{124} \mathrm{I}$.

- Copper-64 $\left({ }^{64} \mathrm{Cu}\right)$ has a physical half-life of about $12.7 \mathrm{~h}$ and decays by $\beta^{-}$emission $(38 \%)$ to Zinc-64 ( $\left.{ }^{64} \mathrm{Zn}\right)$ and by $\beta^{+}$emission $(17.4 \%)$ or electron capture $(44.6 \%)$ to the excited level and the ground state of Nickel-64 $\left({ }^{64} \mathrm{Ni}\right)$. $\beta^{+}$average energy is $278 \mathrm{keV}$, corresponding to a mean range in water of $0.7 \mathrm{~mm}$. The main ${ }^{64} \mathrm{Cu}$ production modes are the following: ${ }^{63} \mathrm{Cu}(\mathrm{n}, \gamma){ }^{64} \mathrm{Cu},{ }^{65} \mathrm{Cu}(\mathrm{n}, 2 \mathrm{n}){ }^{64} \mathrm{Cu},{ }^{64} \mathrm{Zn}(\mathrm{n}, \mathrm{p}){ }^{64} \mathrm{Cu}$, ${ }^{64} \mathrm{Zn}(\mathrm{d}, 2 \mathrm{p}){ }^{64} \mathrm{Cu}$.

The wide and feasible availability of positron emitters radionuclides is a prerequisite for successful application on a routine basis. Fluorine-18 and Gallium-68 are the most used in a clinical setting, so far. Due to its versatility, ${ }^{18}$ F-Fluorodeoxyglucose (FDG), namely a radiolabelled analogue of glucose, is the by far most widely used PET radiopharmaceutical worldwide. FDG is very useful to detect malignant tumours characterized by increased glucose metabolism. However, FDG remains a nonspecific tracer and its uptake is also been observed in many benign conditions, such as infective and inflammatory processes. Therefore, over the last decade, there is a growing interest in researching and using new radiopharmaceuticals, such as radiolabelled amino acids, nucleoside derivatives, choline derivatives, nitroimidazole derivatives and peptides, able to carefully target specific biomarkers. These new generation radiopharmaceuticals allow the analysis of several molecular pathways in tumour biology including metabolism, proliferation, oxygen delivery and protein synthesis as well as receptor and gene expression (Tables 1.4, 1.5 and 1.6). Some examples of PET images with different radiopharmaceuticals are showed in Figs. 1.1 and 1.2. 

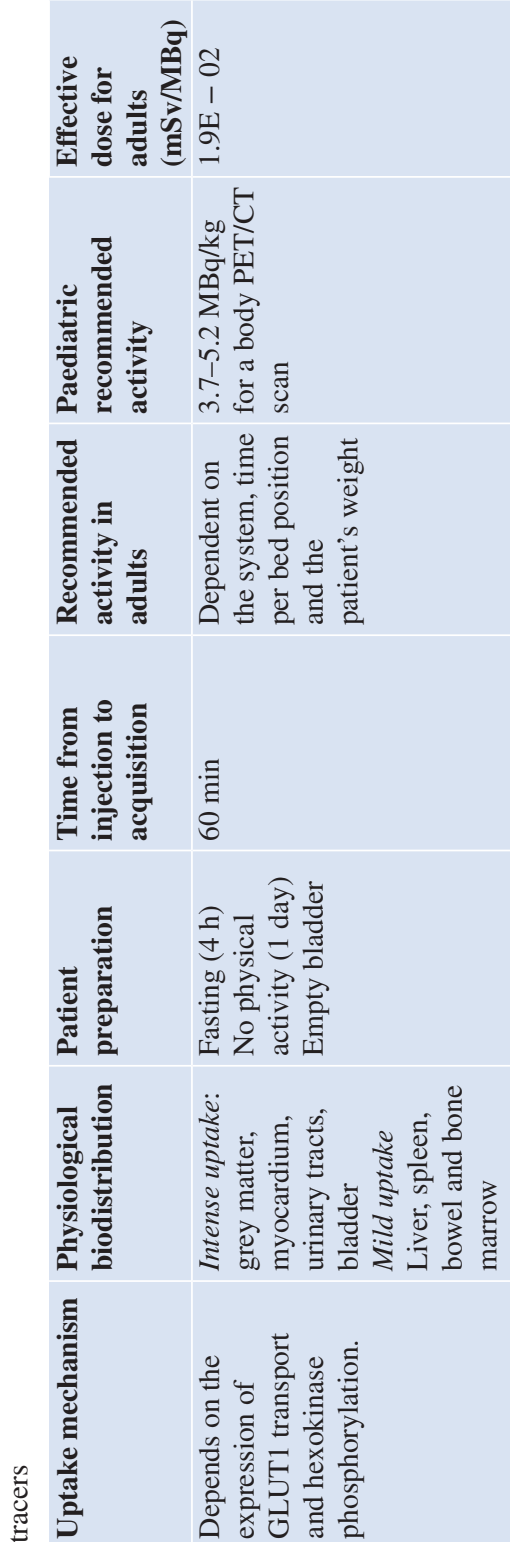

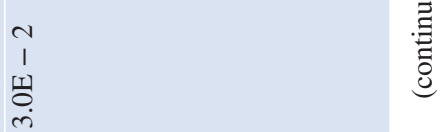

0
ज्ञ
$: 0$
:
0
Z

$\sum_{\substack{+m}}^{\infty}$
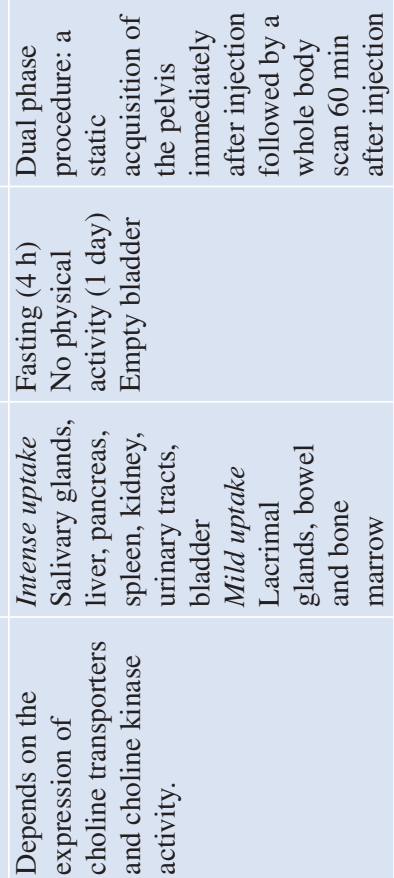

牙.

8

.

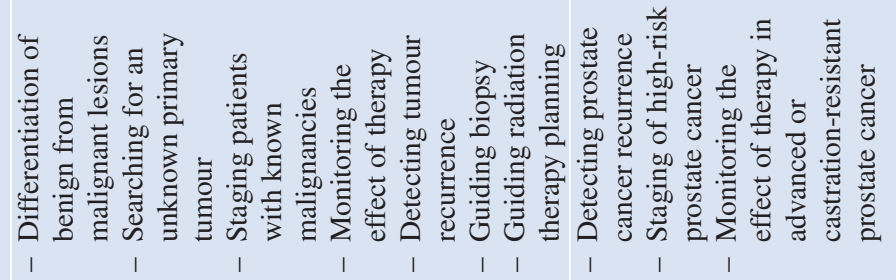

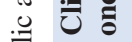

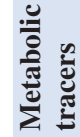

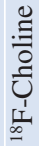



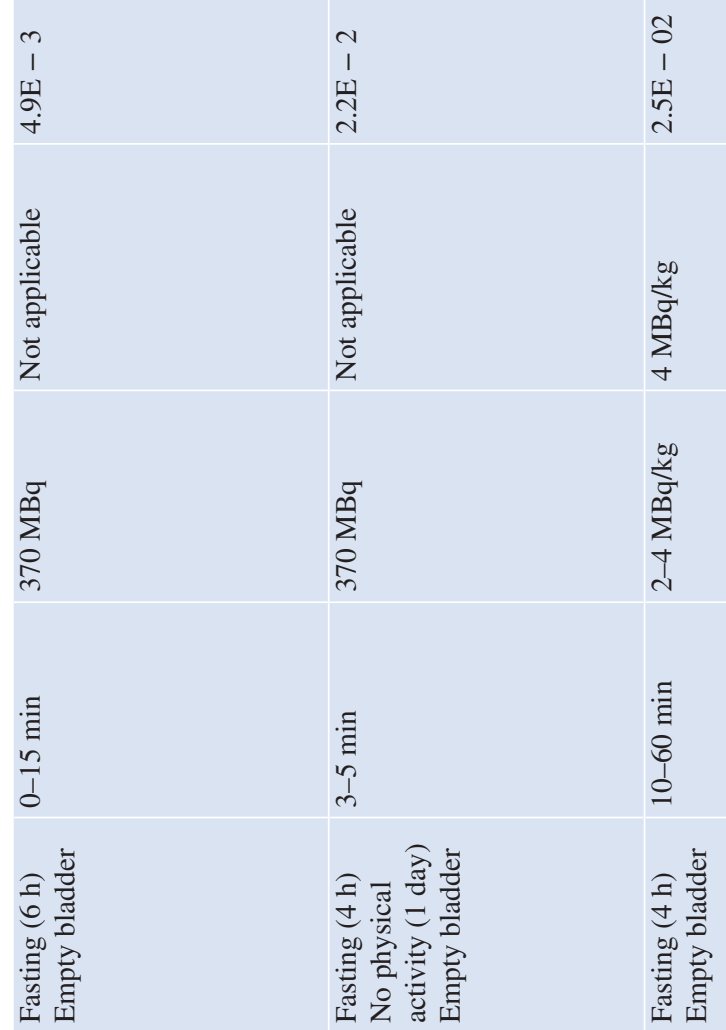

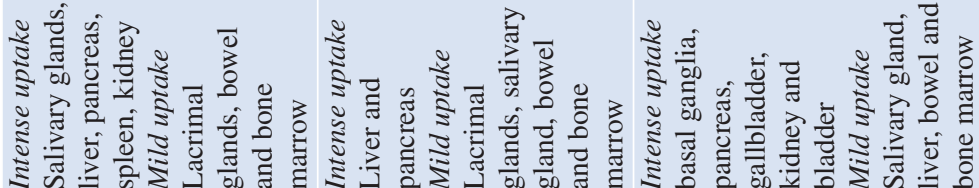
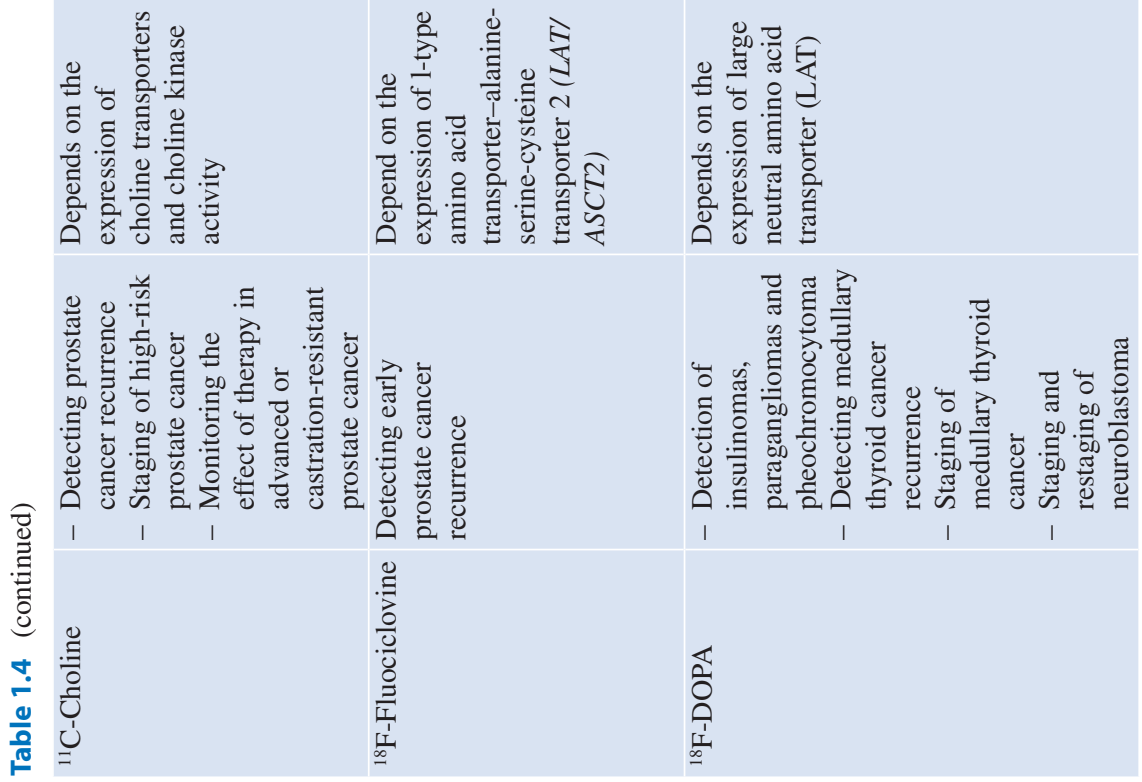

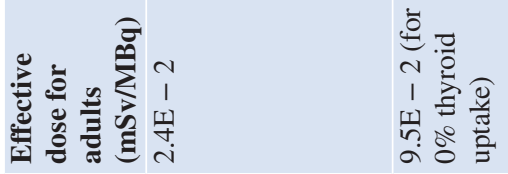

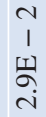

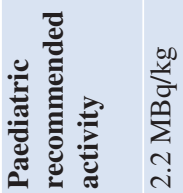

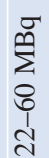

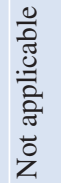
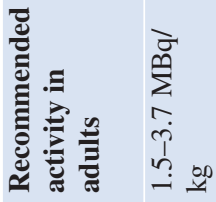

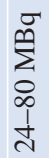

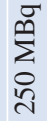

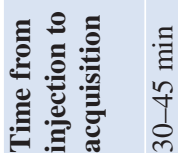

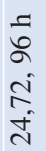

$=$

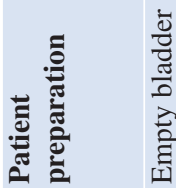

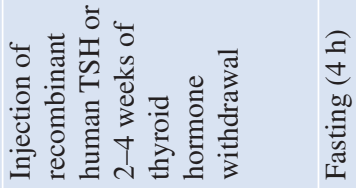

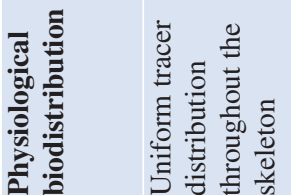

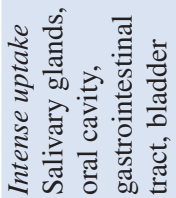

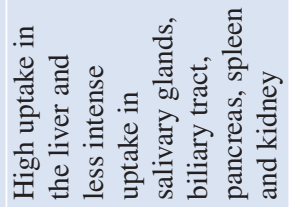

है
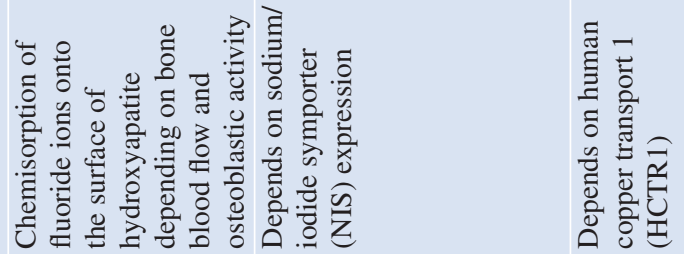

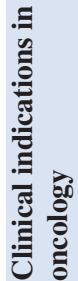

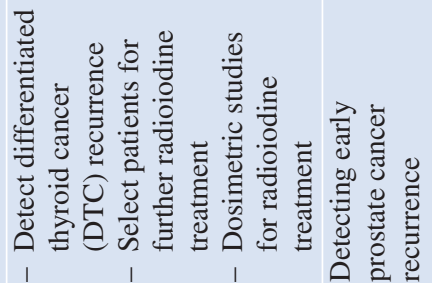

ส

:ैّ

焉焉

$\sum_{\substack{1 \\ \Xi}}^{\bar{I}}$

ర్త్రే 


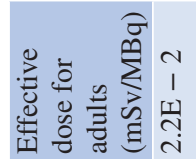

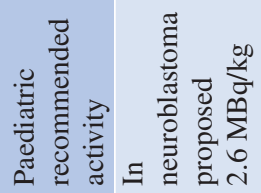

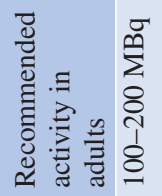

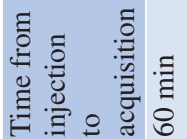

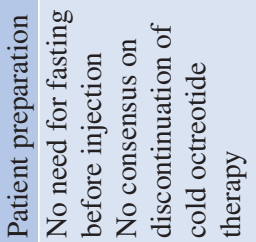

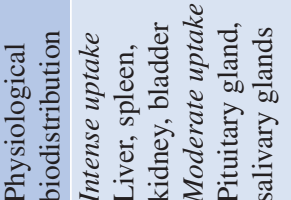

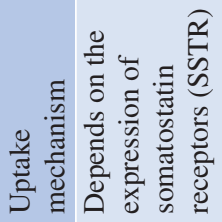

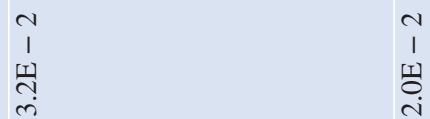

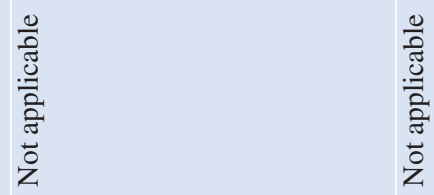

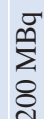

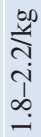

春

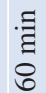

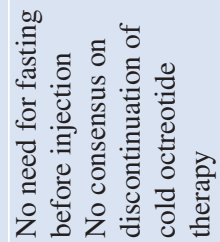

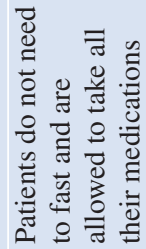

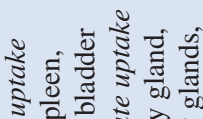

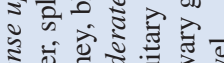

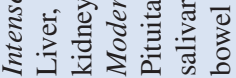

范

ते के

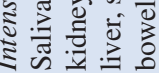

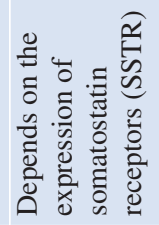

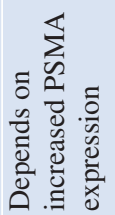

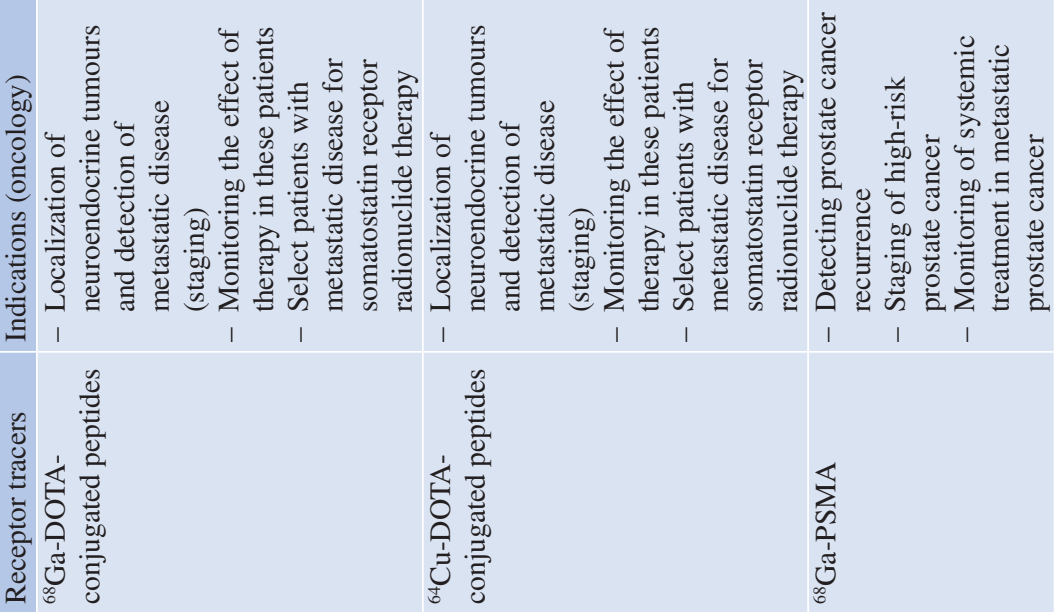




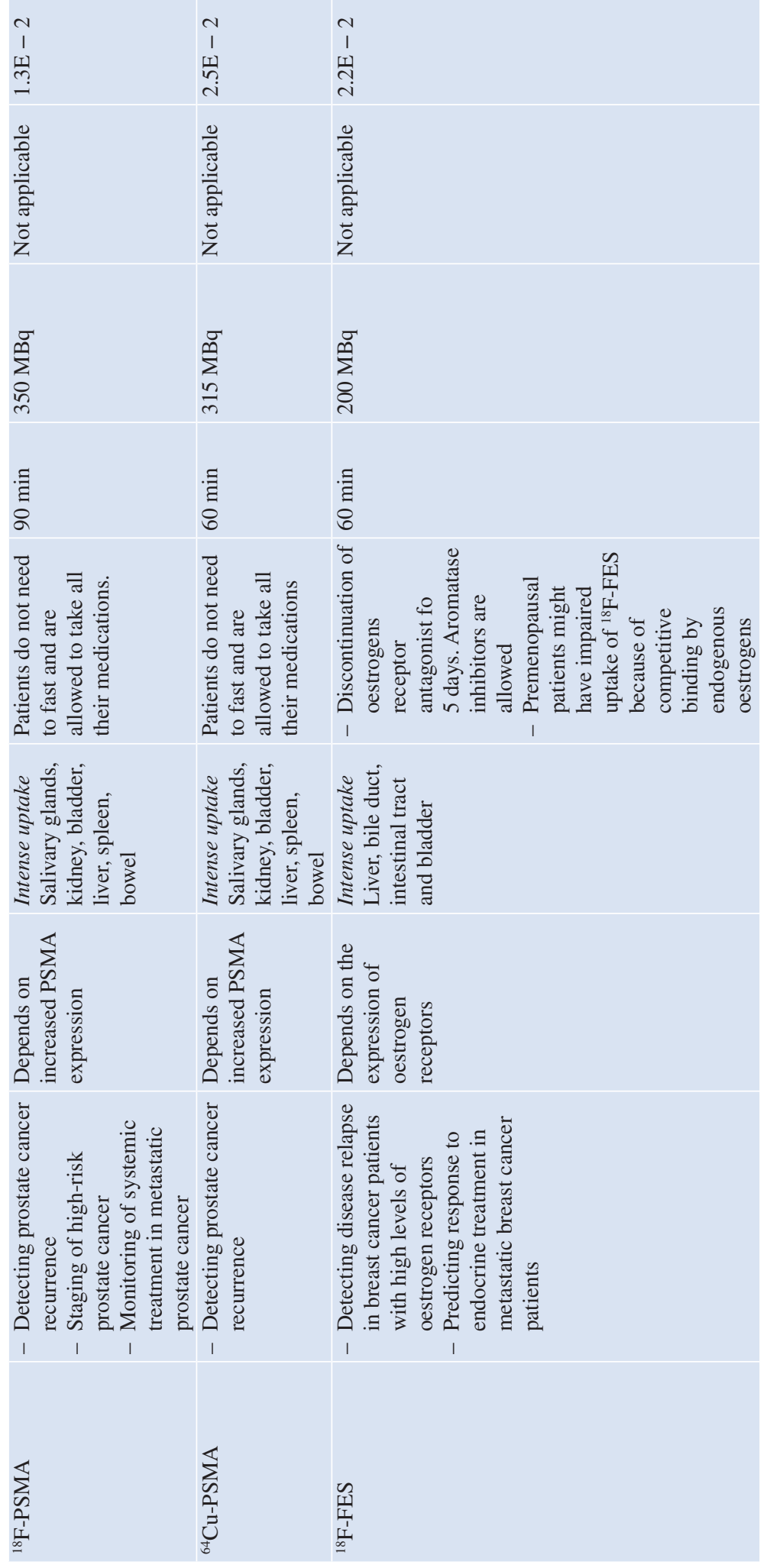



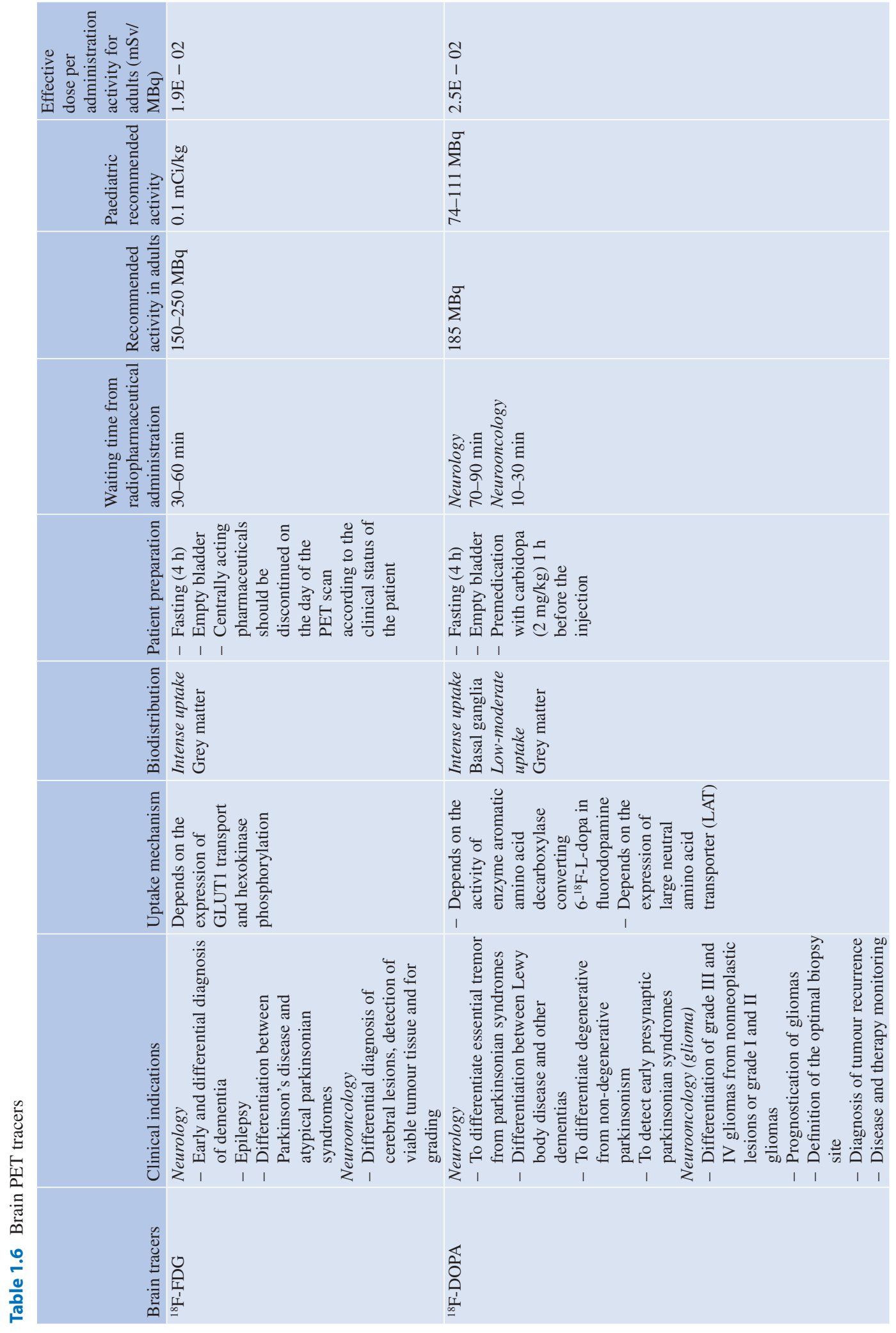


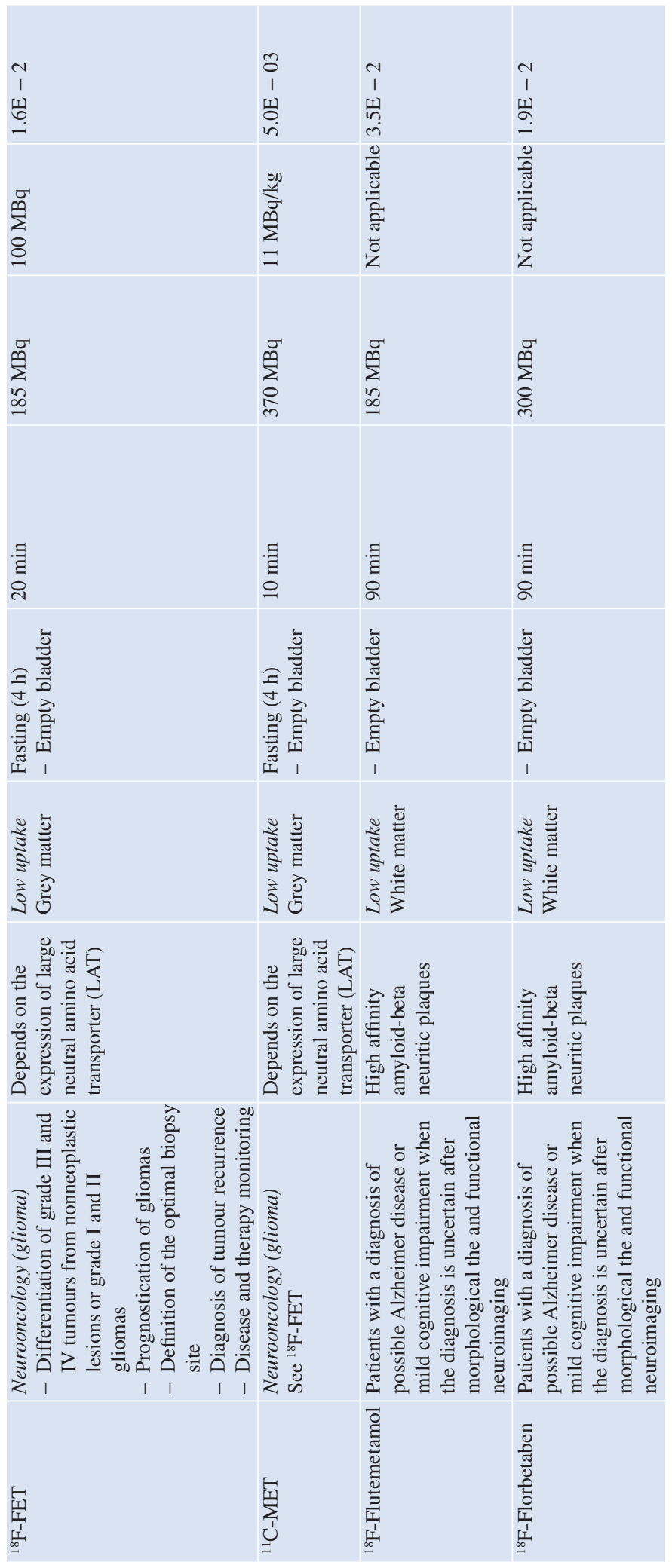


a

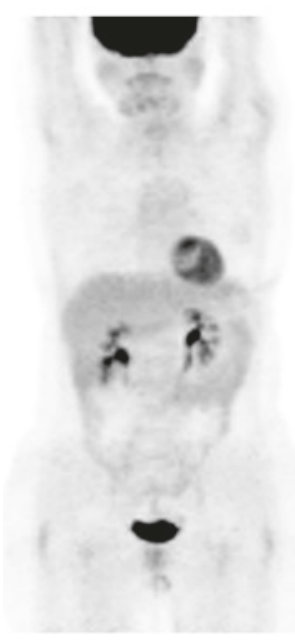

b

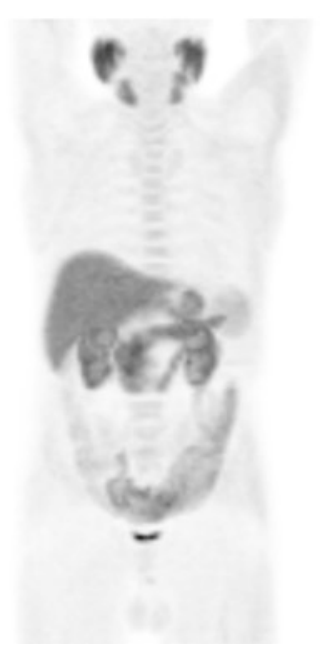

C

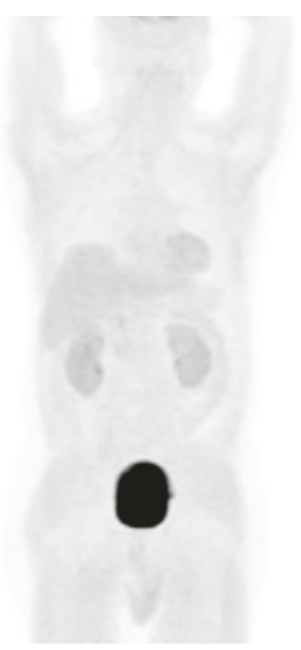

d

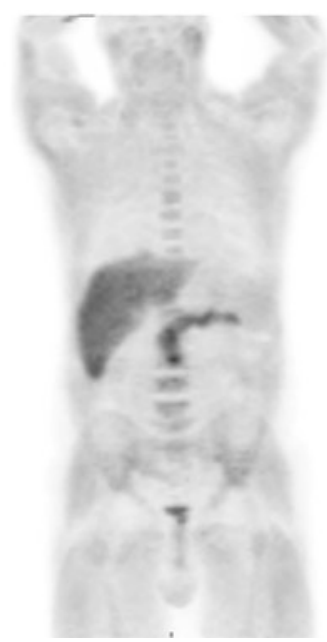

Fig. 1.1 Biodistribution of PET tracers: ${ }^{18} \mathrm{~F}-\mathrm{FDG}(\mathbf{a}),{ }^{18} \mathrm{~F}-\mathrm{FCH}(\mathbf{b}),{ }^{18} \mathrm{~F}$-DOPA $(\mathbf{c}),{ }^{18} \mathrm{~F}$-Fluociclovine $(\mathbf{d})$

a

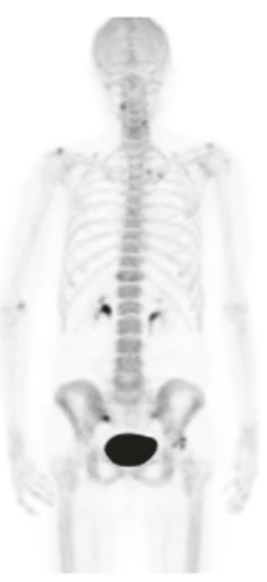

b

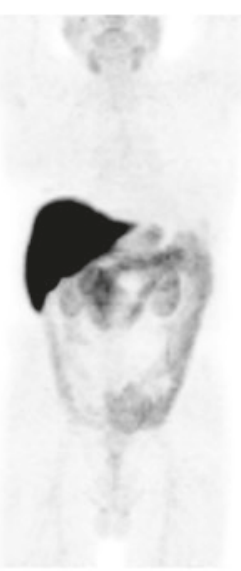

C

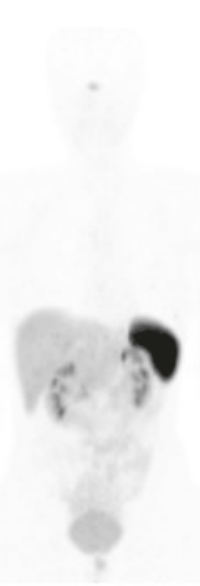

d

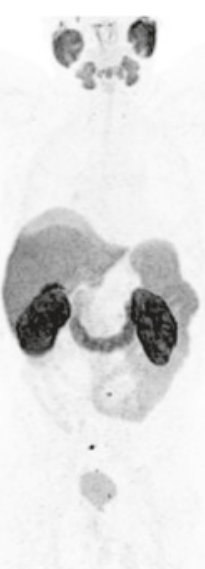

e

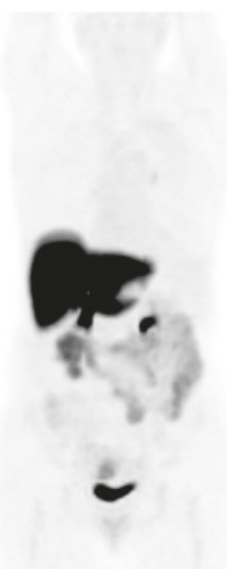

Fig. 1.2 Biodistribution of PET tracers: ${ }^{18} \mathrm{~F}-\mathrm{NaF}(\mathbf{a}),{ }^{64} \mathrm{CuCl}_{2}(\mathbf{b}){ }^{68} \mathrm{Ga}$-DOTATOC $(\mathbf{c}),{ }^{68} \mathrm{Ga}$-PSMA (d), ${ }^{18} \mathrm{~F}$-FES (e)

\section{References}

1. Saha GB. Basics of PET imaging: physics, chemistry, and regulations. New York: Springer; 2010.

2. Zanzonico P. Positron emission tomography: a review of basic principles, scanner design and performance, and current systems. Semin Nucl Med. 2004;34(2):87-111.

3. Slomka PJ, Pan T, Germano G. Recent advances and future progress in PET instrumentation. Semin Nucl Med. 2016;46(1):5-19.
4. Alessio A, Kinahan P. PET imaging reconstruction http://faculty.washington.edu/aalessio/papers/alessioPETRecon.pdf.

5. Waterstram-Rich KE, Christian PE. Nuclear medicine and PET/CT: technology and techniques. St. Louis: Elsevier Mosby; 2012.

6. Li S, Tavares JMRS. Shape analysis in medical image analysis, 51. Lecture notes in computational vision and biomechanics, vol. 14; 2014.

7. Zaidi H, Ojha N, Griesmer J, et al. Design and performance evaluation of a whole-body ingenuity TF PETMRI system. Phys Med Biol. 2011;56(10):3091-106. 
8. Delso G, Furst S, Jakoby B, et al. Performance measurements of the Siemens mMR integrated whole-body PET/MR scanner. J Nucl Med. 2011;52(12):1914-22.

9. Grant AM, Deller TW, Khalighi MM, et al. NEMA NU 2-2012 performance studies for the SiPM-based
ToF-PET component of the GE SIGNA PET/MR system. Med Phys. 2016;43(5):2334.

10. Wadsak W, Mitterhauser M. Basics and principles of radiopharmaceuticals for PET/CT. Eur J Radiol. 2010;73:461-9.

Open Access This chapter is licensed under the terms of the Creative Commons Attribution 4.0 International License (http://creativecommons.org/licenses/by/4.0/), which permits use, sharing, adaptation, distribution and reproduction in any medium or format, as long as you give appropriate credit to the original author(s) and the source, provide a link to the Creative Commons license and indicate if changes were made.

The images or other third party material in this chapter are included in the chapter's Creative Commons license, unless indicated otherwise in a credit line to the material. If material is not included in the chapter's Creative Commons license and your intended use is not permitted by statutory regulation or exceeds the permitted use, you will need to obtain permission directly from the copyright holder.

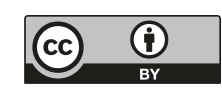

